\title{
Palliative laparoscopic resection of renal cell carcinoma metastatic to the stomach: report of a case
}

Thiago Nogueira Costa, ${ }^{*}$ Flavio Roberto Takeda, Ulysses Ribeiro Jr and Ivan Cecconello

\begin{abstract}
The most common sites of metastases in renal cell carcinoma (RCC) are lung and bone. However, unusual sites, including the stomach, are characteristic of RCC.

This article presents a case of a metastatic RCC (lung and liver) with a symptomatic gastric metastasis treated by a laparoscopic wedge resection (LWR).

A 66-year-old woman, diagnosed with RCC underwent a right nephrectomy. During her follow-up, an upper gastrointestinal (Gl) endoscopy showed an ulcerated lesion at the stomach. A biopsy of the specimen revealed metastatic RCC. The patient underwent a palliative LWR and was discharged home 8 days after surgery.

Therefore, LWR is a relatively simple technique with the advantages of minimal invasive access in the treatment of palliative cases.
\end{abstract}

Keywords: laparoscopic wedge resection, stomach, renal cell carcinoma, metastasis, palliative

\section{Background}

Renal cancer is the 12th leading malignant condition among women and the 7th among men in the United States and accounts for $2.6 \%$ of all cancers. The median survival of renal cell carcinoma (RCC) in metastatic disease is 13 months. A quarter of patients with RCC present with advanced disease, including locally invasive or metastatic cancers. Moreover, a third of patients undergoing resection will have recurrence [1].

The two most common sites of metastases in RCC are lung (up to $60 \%$ of patients) and bone (up to $40 \%$ of metastatic patients). However, unusual sites of metastasis are typical of RCC and include the thyroid, pancreas, skeletal muscle, the skin or underlying soft tissue and virtually any organ. Among these metastatic sites, metastasis to the stomach is quite rare, even in autopsy studies [2-10].

Other metastases to the stomach are rare (ranging from 0.2 to 0.7 ), and they have been reported to result mainly from breast cancers, lung cancers, and melanoma [2,3]. The main symptoms of these metastases are bleeding,

\footnotetext{
*Correspondence: thiagocosta2002@yahoo.com.br

Division of Digestive Surgery - Department of Gastroenterology, São Paulo State Cancer Institute - ICESP-HCFMUSP, University of Sao Paulo School of Medicine, Avenida Doutor Enéas de Carvalho, 255, São Paulo, SP, Brazil
}

anemia, epigastric pain and outlet obstruction [4-8]. In addition, according to Green et al. [11], chemotherapy in patients with unrecognized stomach metastases may result in tumor necrosis followed by perforation of the stomach and rapid death. The treatment options could be embolization, epinephrine injection, endoscopic resection or surgery [12-17], even in palliative patients [7].

Herein, we present and discuss a case of a metastatic RCC (lung and liver) with a symptomatic gastric metastasis treated by a laparoscopic wedge resection (LWR). Our aim is to show a rare case of metastasis to the stomach and highlight the use of a minimal invasive technique for palliative use.

\section{Case presentation}

A 66-year-old woman who was diagnosed with renal cell carcinoma (RCC) underwent a right nephrectomy in January 2006; TNM classification was pT3a pN0 pMx. In June 2008, she presented with a metachronous lung metastasis without any symptoms (only seen in routine image studies), and 5 months later she showed various metastases to the liver, maintaining no symptoms.

By December 2011, she presented symptomatic anemia (hemoglobin level was $5.7 \mathrm{~g} / \mathrm{dl}$ ). An upper gastrointestinal 
(GI) endoscopy showed an ulcerated and friable lesion, covered with fibrin, which measured $25 \mathrm{~mm}$ at the greatest diameter and was located at the greater curvature of the gastric proximal body (Figure 1). The specimen's biopsy histology and immunohistochemistry revealed similar patterns as the $\mathrm{RCC}$ resected from the patient years previous.

Computed tomography showed an exophytic gastric mass in the greater curvature of the stomach (Figure 2a,b).

This patient was hospitalized because of her symptoms. During her stay at the hospital, gastrointestinal bleeding persisted, necessitating a transfusion of six blood units.

Because of the persisting symptoms, she underwent a palliative laparoscopic wedge resection with an auxiliary incision $(3 \mathrm{~cm})$ in the beginning of February 2012. The product of resection was a gastric segment measuring $8.0 \times 5.8 \times$ $2.3 \mathrm{~cm}$, and the lesion, which measured $5.3 \times 2.2 \times 2.3 \mathrm{~cm}$, was ulcerated and covered with fibrin (Figure 3a-c). The histopathological study of the specimen showed margins free of tumor and no perineural invasion. Immunohistochemistry indicated positive Cytokeratin AE1/3, positive CD10, positive CK 7 and positive vimentin.

After surgery, which lasted 40 minutes, the patient was sent to the intensive care unit (ICU) where she stayed for one day. During her hospital stay, she developed a mild pneumonia treated with antibiotic therapy (tazobactan + piperacillin) for 7 days.

She was discharged home 8 days after surgery and returned 1 week later at the outpatient clinic without any symptoms.

\section{Conclusions}

Gastric metastases from disseminated RCC have been reported only infrequently. Pollheimer et al. [5] detected five new cases among 2,082 patients with RCC (0.2\%).

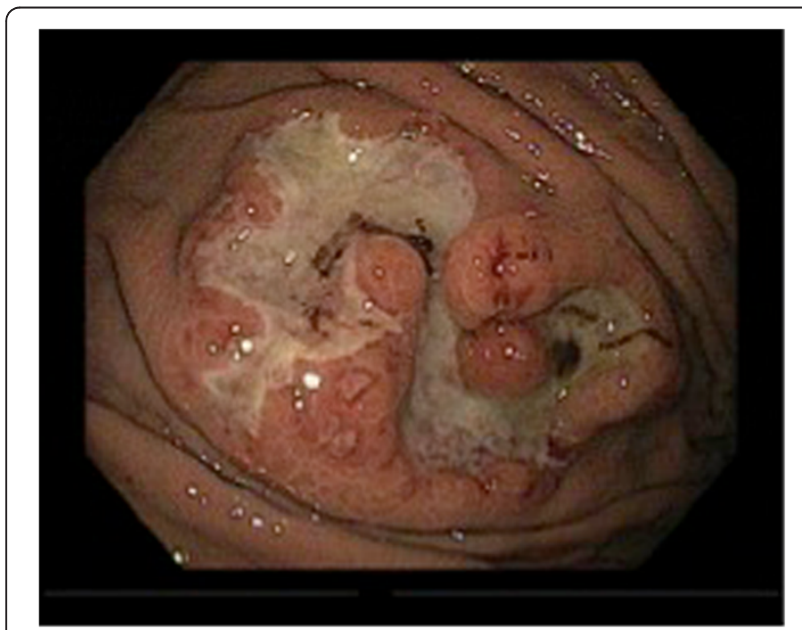

Figure 1 Upper GI Endoscopy. Gastric endoscopy confirmed an ulcerated lesion.
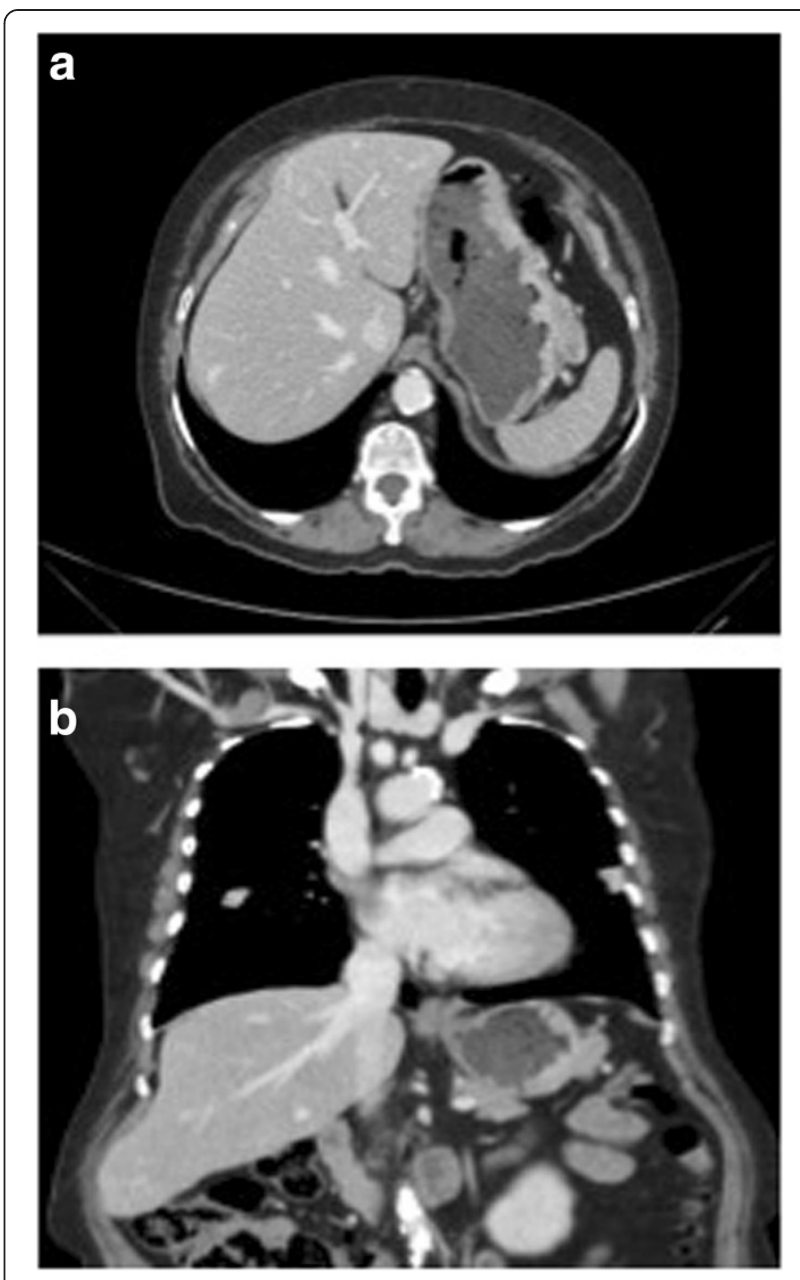

Figure $\mathbf{2}$ Tomography findings. Tomography images showing an exofitic mass in the greater curvature of the stomach. a: axial b: coronal.

The mean (median, range) time to diagnosis of gastric metastases in the present case and those reported previously was 6 (4.7, 0.1 to 20) years; other studies showed even later appearance: 6.6 years (range: 2 years to 14 years) [7]. There are few studies (around 20) showing the association between gastric metastasis from RCC and other metastasis of the same tumor. Kim et al. in 2012 showed various case reports of gastric metastasis resection and other possible approaches to treating this disease [18].

The most frequent gastric tumor locations are in the body and gastric fundus, and single tumors predominate over multiple [3]; our patient had a solitary tumor at the proximal body on the greater curvature. The main symptoms, as described before, are upper GI bleeding (presenting as anemia, melena or upper hemorrhage) or gastric outlet obstruction [2].

There are various types of treatment such as embolization, epinephrine injection or systemic therapy (for example, octreotide and sorafenib) [12-17]. Even in 

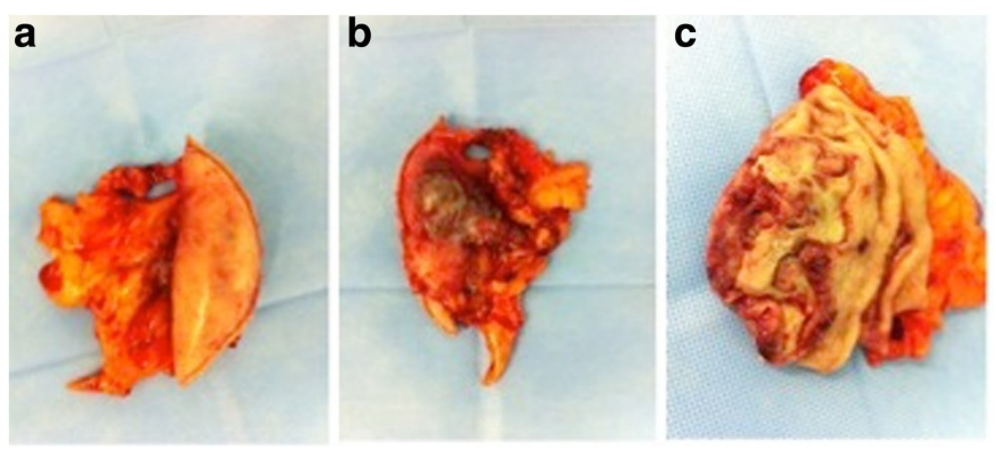

Figure 3 Macroscopic view. Macroscopic appearance of resected specimen. a: posterior view b: anterior view c: open view.

patients without curative approach, surgery could be the elective treatment [7]. However, there are many issues involving the surgical approach, such as mortality, morbidity, the size and number of the metastatic disease, and patient condition. Thus, the laparoscopic approach appears to be a good alternative in these patients, particularly in palliative cases.

Examples of laparoscopic treatment of metastasis to the stomach in the literature include cases of melanoma [19] and choriocarcinoma [20], both treated by laparoscopic wedge resection (LWR) with good results and no perioperative mortality or morbidity. Laparoscopic resections for metastasis of RCC to other organs have also been described; an example is a distal pancreatectomy that showed great benefit [21].

The criteria for LWR in the stomach are tumor size up to $50 \mathrm{~mm}$ and tumor location on the lesser or greater curvature or on the anterior aspect of the gastric body [22]. Tumors near the pylorus and cardia are not suitable for LWR because of the technical difficulty and risk of complications [23]. Our patient, however, was eligible for the procedure.Laparoscopic wedge resection (LWR) is a simple technique and offers advantages of laparoscopic surgery, including a shorter hospital stay and early return to normal activity with minimal morbidity and mortality. The indications for this technique may be extended to the palliative resection of metastatic gastric tumors in selected patients.

\section{Consent}

Written informed consent was obtained from the patient for publication of this Case Report and any accompanying images. A copy of the written consent is available for review by the Editor-in-Chief of this journal.

\section{Abbreviations}

GI: gastrointestinal; ICU: intensive care unit; LWR: laparoscopic wedge resection; RCC: renal cell carcinoma.

\section{Competing interests}

The authors declare that they have no competing interests.

\section{Authors' contributions}

TNC obtained patient consent, organized clinical photographs, wrote the first draft of the manuscript and performed the literature search. FRT examined the surgical specimen, took the photograph of the specimen and helped with manuscript preparation. URJ retrieved articles and helped with the manuscript preparation. IC edited the manuscript and had overall responsibility for patient care. All authors read and approved the final manuscript.

\section{Acknowledgements}

This research was not supported by any funds.

Received: 5 February 2014 Accepted: 20 July 2014

Published: 23 December 2014

\section{References}

1. Cohen HT, McGovern FJ: Renal-cell carcinoma. N Engl J Med 2005, 353:265.

2. Menuck LS, Amberg JR: Metastatic disease involving the stomach. Am J Dig Dis 1975, 20:903-913.

3. Campoli PM, Ejima FH, Cardoso DM, Silva OQ, Santana Filho JB, Queiroz Barreto PA, Machado MM, Mota ED, Araujo Filho JA, Alencar Rde C, Mota OM: Metastatic cancer to the stomach. Gastric Cancer 2006, 9:19-25.

4. Sullivan WG, Cabot EB, Donohue RE: Metastatic renal cell carcinoma to stomach. Urology 1980, 15:375-378.

5. Pollheimer MJ, Hinterleitner TA, Pollheimer VS, Schlemmer A, Langner C: Renal cell carcinoma metastatic to the stomach: single-centre experience and literature review. BJU Int 2008, 102:315-319.

6. Saidi RF, Remine SG: Isolated gastric metastasis from renal cell carcinoma 10 years after radical nephrectomy. J Gastroenterol Hepatol 2007, 22:143-144.

7. Haffner J, Morel JF, Maunoury V, Caty A, Biserte J, Villers A: Gastric or duodenal metastases from clear cell renal cell carcinoma. Report of two cases and review of the literature. Prog Urol 2007, 17:1305-1309.

8. Kibria R, Sharma K, Ali SA, Rao P: Upper gastrointestinal bleeding revealing the stomach metastases of renal cell carcinoma. $J$ Gastrointest Cancer 2009, 40:51-54.

9. Sakurai K, Muguruma K, Yamazoe S, Kimura K, Toyokawa T, Amano R, Kubo N, Tanaka H, Yashiro M, Ohira M, Hirakawa K: Gastric metastasis from renal cell carcinoma with gastrointestinal bleeding: a case report and review of the literature. Int Surg 2014, 99:86-90.

10. Eslick GD, Kalantar JS: Gastric metastasis in renal cell carcinoma: a case report and systematic review. J Gastrointest Cancer 2011, 42:296-301.

11. Green LK: Hematogenous metastases to the stomach. Cancer 1990, 65:1596-1600.

12. Blake M, Owens A, Donoghue DP, MacErlean DP: Embolotheraphy for massive upper gastrointestinal haemorrhage secondary to metastatic renal cell carcinoma: report of three cases. Gut 1995, 37:835-837.

13. Picchio M, Paioletti A, Santini E, lacoponi S, Cordahi M: Gastric metastasis from renal cell carcinoma four - teen years after radical nephrectomy. Acta Chir Belg 2000, 100:228-230.

14. Lamb GW, Moss J, Edwards R, Aitchison M: Octreotide as an adjunct to embolization in the management of recurrent bleeding upper gastrointestinal metastases from primary renal cell cancer. Int Urol Nephrol 2005, 37:691. 
15. Patel PH, Chaganti RSK, Motzer RJ: Targeted therapy for metastatic renal cell carcinoma. Br J Cancer 2006, 94:614-619.

16. Pezzoli A, Matarese V, Boccia S, Simone L, Gullini S: Gastrointestinal bleeding from gastric metastasis of renal cell carcinoma, treated by endoscopic polypectomy. Int J Surg Case Rep 2012, 3:601-604.

17. Klatte T, Kroeger N, Zimmermann U, Burchardt M, Belldegrun AS, Pantuck AJ: The contemporary role of ablative treatment approaches in the management of renal cell carcinoma (RCC): focus on radiofrequency ablation (RFA), high-intensity focused ultrasound (HIFU), and cryoablation. World J Urol 2014, 32:597-605. Epub 2014 Apr 4

18. Kim MY, Jung HY, Choi KD, Song HJ, Lee JH, Kim DH, Choi KS, Kim SA, Lee GH, Kim JH: Solitary synchronous metastatic gastric cancer arising from t1b renal cell carcinoma: a case report and systematic review. Gut Liver 2012, 6:388-394.

19. Date RS, Griffiths EA, Pritchard SA, McL Welch I: Combined endoscopic and laparoscopic approach for palliative resection of metastatic melanoma of the stomach. World I Surg Oncol 2006, 4:20

20. Galloway SW, Yeung EC, Lau JY, Chung SC: Laparoscopic gastric resection for bleeding metastatic choriocarcinoma. Surg Endosc 2001, 15:100.

21. Hernandez DJ, Kavoussi LR, Ellison LM: Laparoscopic distal pancreatectomy for metastatic renal cell carcinoma. Urology 2003, 62:551.

22. Otani Y, Ohgami M, Igarashi N, Kimata M, Kubota T, Kumai K, Kitajima M, Mukai M: Laparoscopic wedge resection of gastric sub mucosal tumors. Surg Laparosc Endosc Percutan Tech 2000, 10:19-23.

23. Kitano S, Shiraishi N: Current status of laparoscopic gastrectomy for cancer in Japan. Surg Endosc 2004, 18:182-185.

doi:10.1186/1477-7819-12-394

Cite this article as: Costa et al:: Palliative laparoscopic resection of renal cell carcinoma metastatic to the stomach: report of a case. World Journal of Surgical Oncology 2014 12:394.

\section{Submit your next manuscript to BioMed Central and take full advantage of:}

- Convenient online submission

- Thorough peer review

- No space constraints or color figure charges

- Immediate publication on acceptance

- Inclusion in PubMed, CAS, Scopus and Google Scholar

- Research which is freely available for redistribution 